\title{
VIH no feminino: vivência psicológica
}

\author{
HIV and the female gender: the psychological experience \\ VIH en el feminino: vivencia psicológica
}

\section{Sílvia do Rosário Piteira Natário de Lourenço', Henrieue Guilherme Martins Afonso' \\ 'Centro Hospitalar de Setúbal. Serviço de Puerpério e Ginecologia. Setúbal, Portugal Hospital São João. Serviço de Angiologia e Cirurgia Vascular, Porto, Portugal}

Submissão: 10/03/2008

Aprovação: 03/12/2008

\section{RESUMO}

A SIDA coloca Questões sociais, humanitárias e jurídicas cruciais, e ameaça alterar seriamente fundamentos da estrutura social de tolerância e entendimento Que sustém a vida das nossas sociedades. A partir de uma contextualização dos aspectos clínicos e epidemiológicos do VIH/SIDA, este artigo de revisão bibliográfica faz uma abordagem da vivência psicológica e das implicações da infecção com o Vírus da Imunodeficiência Humana AdQuirida na mulher grávida.

Descritores: HIV; AIDS; Saúde da mulher; Gravidez.

\section{ABSTRACT}

AIDS raises a social issue, humanitarian, legal, and threatens to change the social structure founding of tolerance and understanding, that sustains the life of our societies. From a clinical and epidemiological background of HIV/AIDS, this article of literature review makes an approach about psychological experience and implication of the Human Immunodeficiency Virus infection in pregnant woman.

Descriptors: HIV; AIDS; Women's health; Pregnancy.

\section{RESUMEN}

SIDA plantea cuestiones sociales, humanitarias y jurídicas fundamentales, y amenaza cambiar gravemente motivos de la estructura social de tolerancia y comprensión, Que sustenta la vida de nuestra sociedad. Desde una contextualización de los aspectos clínico y epidemiológicos del VIH / SIDA, en este artículo de revisión bibliográfica se hace un enfoque acerca de la v psicológica y la implicación de la infección por el Virus de Inmunodeficiencia Humana AdQuirida en la mujer embarazada.

Descriptores: VIH; SIDA; Salud e la mujer; Embarazo. 


\section{INTRODUÇÃO}

A grande praga do século XXI, conhecida como Vírus da Imunodeficiência Humana (VIH), ataca todo o sistema imunológico responsável pela defesa do organismo. O Sindroma da Imunodeficiência AdQuirida (SIDA) é também conhecido como sendo um vírus contagioso, propagando-se através de determinados comportamentos específicos, expandindo-se súbita e silenciosamente $^{(1,2)}$, o Que the granjeou, rapidamente, o estatuto de epidemia internacional.

A inteligência deste vírus tem sido, até ao momento, um obstáculo para todas as organizações Que procuram uma cura, uma vez Que VIH acaba sempre por vencer a tecnologia. Adicionalmente, como não há certeza em relação ou à sua progressão(3), este vírus tornou-se na mais letal de todas as epidemias até hoje conhecidas, já tendo dizimado, por todo o mundo, milhões de indivíduos, famílias, comunidades e sociedades, continuando a infectar muitos mais, independentemente da idade, cor e estatuto social.

Tendo sido inicialmente detectada em homossexuais, toxicodependentes e marginais, a SIDA tem conotações psicológicas subjectivas e indissociáveis da representação mental Que se tem destas populações, confundindo-se a doença com o seu portador. Sabemos hoje, Que a doença se alastrou a heterossexuais, não forçosamente promíscuos do ponto de vista sexual, a não homossexuais, a não drogados, não marginais, a adolescentes, Que redobra a nossa responsabilidade na tomada de medidas preventivas e nos obriga não só a revisitar não só o comportamento sexual, mas também aQuilo Que o determina a nível intrapsíquico ${ }^{(4)}$.

Os resultados de pesquisas efectuadas sugerem Que os casos de infecção pelo VIH/SIDA atribuíveis à transmissão heterossexual estão a aumentar mais rapidamente do Que QualQuer outra categoria de exposição. Assim, verifica-se o aumento de indivíduos infectados do sexo feminino ${ }^{(5)}$.

Cabral e Leal ${ }^{(6)}$ salientam o facto de vários autores referirem Que no final da segunda década da pandemia as mulheres serão indiscutivelmente as mais afectadas, por razões de ordem biológica, epidemiológica e social.

$\mathrm{O}$ risco das mulheres em relação ao VIH não pode ser separado das desigualdades sociais existentes nem do contexto relacional em Que elas vivem, pelo Que a prevenção da SIDA nas mulheres está intimamente associado às necessidades de mudança sociais e culturais $^{(7)}$.

Face a um projecto de vida ameaçado ou restringido pela presença de uma infecção pelo VIH, surge muitas vezes na mulher o desejo de deixar algo dela para o parceiro ou para o mundo. Neste contexto, a decisão de conceber uma criança ou de evitar a sua concepção na presença de uma infecção VIH é extremamente pessoal, no entanto é geralmente pautada por um conflito interno Que será provavelmente marcado pela ansiedade e ambivalência ${ }^{(6)}$.

A gravidez dimensiona os papéis e as relações da mulher num novo contexto, torna-a mais dependente da ajuda de um sistema social de apoio e cria-lhe necessidades intensas de atenção e aceitação por parte dos outros. $\mathrm{O}$ modo como a sociedade a olha pode afectar profundamente a sua experiência e as possibilidades são imensas e imprevisíveis.

\section{ASPECTOS CLINICOS E EPIDEMIOLÓGICOS DO VIH/SIDA}

\section{Caracterização do VIH/SIDA}

O VIH é um retrovirus Que enfraquece as defesas imunitárias do corpo destruindo os linfócitos CD4 (células - T). Estes linfócitos CD4 constituem um grupo de células brancas do sangue Que normalmente ajudam o organismo a defender-se contra os ataques das bactérias, vírus e outros germes através da coordenação do sistema imunológico ${ }^{(8)}$. Quando o VIH destrói os linfócitos CD4, o corpo torna-se vulnerável a diversos tipos de infecções oportunistas, ou seja, infecções Que têm a oportunidade de invadir o corpo humano porque as defesas imunitárias estão enfraquecidas. Do ponto de vista médico, a infecção pelo VIH aumenta o risco de determinados cancros, de doenças neurológicas, debilitação do corpo e consequente morte. $\mathrm{O}$ espectro lato de sintomas e doenças Que podem ocorrer na eventualidade da infecção pelo VIH e Que destroem de modo significativo as defesas imunitárias, é designado por $\operatorname{SIDA}^{(9,10)}$.

A evolução do VIH para a SIDA varia no tempo, não obstante, é possível distinguir as seguintes fases de evolução(1): a doença inicial de seroconversão viral seguida de uma fase assintomática; o aumento dos gânglios linfáticos, com o início de infecções oportunistas e finalmente o aparecimento da SIDA.

De acordo com $A$ varez ${ }^{(12)}$, a doença não segue obrigatoriamente esta sequência, sendo Que actualmente com os novos esquemas terapêuticos, a infecção pode existir durante muitos anos sem se manifestar, assemelhando-se a um estado de doença crónica. Neste sentido o VIH pode estar latente por um período de 8 a $1 \mathrm{I}$ anos, durante o Qual as pessoas infectadas podem estar completamente assintomáticas, mas capazes de transmitir o vírus a outras pessoas ${ }^{3}$. Este autor acrescenta ainda, Que Quando o vírus é activado provoca uma diminuição da imunidade celular e progressiva imunosupressão.

Fazem parte das características clínicas da doença VIH o aumento dos gânglios linfáticos, febres periódicas, incluindo suores nocturnos, perda de peso, fadiga constante, diarreia, redução do apetite e aftas na boca. O VIH pode também afectar o sistema nervoso central, causando lesões cerebrais e medulares.

\section{Dados Epidemiológicos}

A Comissão Nacional de Luta Contra a SIDA, com base em dados da Organização Mundial de Saúde (OMS), afirmou Que em todo o mundo já foram infectadas cerca de 40 milhões de pessoas $^{(13)}$, o Que não inclui aqueles casos Que não chegam ao conhecimento público, ou em Que simplesmente, não existe QualQuer estatística, uma vez Que Quem contrai esta doença, para não ser estigmatizado, não informa as entidades responsáveis. Mais recentemente, o relatório epidemiológico de organizações como a UNAIDS (Joint United Nations Programme on HIV/AIDS) e a OMS (WHO - World Health Organization) ${ }^{(14)}$, publicado em 2003 (AIDS Epidemic Update, December, 2003), mostra que a nível mundial o número de pessoas infectadas com SIDA e cerca de 42 milhões, o número de novas pessoas infectadas durante 2003 foi de 5 milhões e o número de mortes causadas pela doença em 2003 foi de 3 milhões.

Na Europa, e de acordo com o relatório de 2006 do European Centre for the Epidemiological Monitoring of HIV/AID ${ }^{(15)}$, foram 
diagnosticados em 2005 um total de 80.758 novos casos de infecção por VIH, sendo Que os países Que mais contribuíram para estes valores foram a Estónia, Portugal, a Federação Russa e a Ucrânia.

Em Portugal a notificação dos casos de infecção pelo VIH é voluntária e realizada pelo médico assistente, procedendo-se ao registo dos casos declarados. Este registo é incompleto, sobretudo no Que se refere aos casos assintomáticos, mas permite-nos observar a tendência crescente do número de casos e de mulheres infectadas.

De acordo com o relatório de 2006 do European Centre for the Epidemiological Monitoring of HIV/AIDS ${ }^{(15)}$, dos 10.495 .000 habitantes de Portugal, 31.000 estão infectados com o vírus HIV, dos Quais 1.300 são indivíduos do sexo feminino ${ }^{(15)}$. Já em Junho de 2007, o Instituto Nacional Dr. Ricardo Jorge \& Ministério da Saúde ${ }^{(16)}$, emite um documento Que refere encontrarem-se notificados em Portugal 31.677 casos de Infecção VIH/SIDA, nos diferentes estádios da infecção Que incluem os portadores assintomáticos, os portadores sintomáticos não SIDA e os portadores de SIDA.

Este relatório acrescenta ainda Que em Portugal se verifica uma tendência evolutiva decrescente no Que concerne à transmissão do VIH associada aos casos de toxicodependência, em contraposição a uma tendência crescente de transmissão heterossexual.

Em Portugal o primeiro caso de SIDA no sexo feminino foi diagnosticado em 1985, registando-se 10 anos depois mais de 360 casos em mulheres ${ }^{(17)}$. No nosso país, o sector de pessoas com SIDA com maior crescimento são as mulheres com idades compreendidas entre os 20 e os 49 anos. Em Junho de 2004 o Instituto Nacional Dr. Ricardo Jorge \& Ministério da Saúde ${ }^{(16)}$, reportou 1.918 casos de mulheres com SIDA, sendo Que $86.8 \%$ destas mulheres se encontram numa faixa etária activa do ponto de vista sexual e profissional. A análise epidemiológica sugere Que, nacionalmente, as mulheres representam uma grande proporção dos casos de SIDA.

\section{VIH NAS MULHERES}

As mulheres têm vindo a ser infectadas com o Vírus da Imunodeficiência Humana (VIH) desde os primórdios da epidemia.

Em 1990, a OMS, estimou Que o número de mulheres infectadas pelo VIH representaria um terço dos casos mundiais, Já no final do ano de 2002, elas constituíam, de acordo com a OMS cerca de 19.2 milhões dos 40 milhões de pessoas Que se encontram infectadas com o $\mathrm{VIH}^{(15)}$, representando aproximadamente $50 \%$ dos 38.6 milhões de adultos Que vivem com o VIH/SIDA.

\section{Factores Associados à Infecção}

A transmissão do vírus é muito mais facilitada de homem para mulher, cerca de duas a vinte vezes em comparação com relações mulher-homem $^{(18)}$. Este risco está relacionado com o facto de a área de exposição da mucosa vaginal, ser bastante elevado.

As mulheres estão em maior risco de contraírem o VIH durante as relações heterossexuais do Que os homens por varias razões ${ }^{(19,20)}$. De acordo com estes autores, o sémen tem uma maior Quantidade de linfócitos Que podem ser infectados do Que o fluido vaginal, para além de Que fluido seminal também tem um efeito imunossupressivo sobre a mucosa Que facilita a absorção do VIH. Em segundo lugar, as mulheres têm uma área mais lata de mucosa disponível para a penetração do VIH (vagina e cervix), mas a única mucosa exposta nos homens e a uretra. A mucosa vaginal pode sofrer feridas microscópicas durante as relações sexuais, tornando a transmissão mais provável.

Por último, as mulheres são biologicamente mais susceptíveis às infecções porQue certas características do ambiente vaginal, como por exemplo, a temperatura, podem propiciar o desenvolvimento de alguns organismos, acrescendo ainda Que a infecção é inicialmente assintomática, o Que atrasa o diagnóstico e o tratamento.

Factores psicológicos e psicossociais associados à transmissão, aQuisição e progressão do VIH, podem também explicar as diferenças entre homens e mulheres na evolução clínica e na mortalidade. A transmissibilidade pode ser determinada por características individuais, pelo vírus, ou por ambas.

Alguns factores biológicos parecem aumentar a susceptibilidade à infecção pelo VIH nas mulheres, nomeadamente outras Infecções Sexualmente Transmissíveis (IST's) e infecções urinárias, para além disso, alguns estudos embora contraditórios, apontam para a gravidez como facilitador da passagem da imunodeficiência em mulheres seropositivas.

No Que concerne aos factores psicológicos, destaca-se o stress, no sentido em que este parece poder acelerar a passagem para a fase de imunodeficiência. Como se sabe, há diferenças entre os sexos no Que respeita ao confronto com o stress, ajustamento psicológico e situações indutoras de stress e a alterações fisiológicas associadas ao stress, pelo Que é plausível pensar-se em vulnerabilidade às consequências do stress sobre a imunidade possa ser diferente no sexo feminino(21). Finalmente, em função dos estilos de vida e estatuto social, pode acontecer Que as mulheres seropositivas possam estar mais expostas a acontecimentos indutores de stress, nomeadamente relacionados com situações de pobreza e/ou exclusão social. Mais ainda, podemos salientar Que o estatuto desigual das mulheres tem implicações sexuais, nomeadamente por motivos sociais e culturais, a assertividade das mulheres no plano sexual não é bem aceite pela maioria da comunidade masculina ${ }^{(22)}$.

De acordo com Richardson ${ }^{(23)}$ é ainda importante salientar que o suporte social tem sido relacionado com o bem-estar psicológico e com a saúde e, em geral, tem sido referido Que as mulheres possuem níveis mais altos de suporte social do Que os homens. No entanto há evidências de Que as mulheres afectadas pelo VIH tendem a estar significativamente isoladas, não só porQue são menos, mas também porQue tendem a estar geograficamente mais distribuídas.

\section{Gravidez e VIH}

A gravidez não é uma experiência estática nem breve, mas plena de crescimento e mudanças, enriquecimento e desafio. De acordo com Canavarro ${ }^{(24)}$, a gravidez transcende o momento da concepção e diz respeito a um processo Que corresponde a um período Que medeia a concepção e o parto. É uma época em Que a mulher se prepara para ser mãe, ensaiando cognitivamente papéis e tarefas maternas, iniciando um processo de reestruturação de relações 
para incluir um novo elemento, bem como incorporar o filho na sua identidade.

Assim, a gravidez é simultaneamente uma transformação biológica social e pessoal, Que põe a mulher em contacto com sentimentos e significados latentes desde o nascimento, repentinamente evocados por uma mudança física poderosa, Que se repercute através de todos os outros níveis psicológicos.

Na vida da mulher, o desejo de ter um filho resulta do desejo de conservar uma imagem idealizada de si mesma, como um ser completo e omnipotente, o Qual começa a satisfazer-se já na gravidez, na medida em Que esta dá à mulher a possibilidade de se sentir plena e completa, de experimentar a potência e produtividade do seu corpo. A gravidez faz acrescentar à sua imagem corporal uma nova dimensão, Que pode ser exibida.

No entanto, esse desejo só é, efectivamente realizado através da criança, começando a mãe por ver a criança como uma extensão do seu próprio self. A criança corresponde à esperança de autoduplicação, de imortalidade ${ }^{(25)}$.

A SIDA, por outro lado é uma doença incurável, contagiosa e com mortalidade elevada, onde um grupo significativo de mulheres afectadas apresenta uma problemática psicológica prévia, Que tenderá a descompensar com o impacto da seropositividade ou da SIDA. O suporte social tende a ser limitado, Quer por distanciamento prévio da família de origem Quer por pertença a grupos marginalizados, ou ainda, por a situação poder condicionar sentimentos ambivalentes ou mesmo atitudes de rejeição por parte da comunidade ${ }^{(26)}$.

Ter um filho é para muitas mulheres um projecto central do ser mulher, contudo, no contexto de uma infecção VIH, esse desejo de ser mãe tem de ser pesado em relação ao conhecimento de Que poderá passar o vírus para a criança e Que é pouco provável Que sobreviva tempo suficiente para realizar plenamente o seu papel materno ${ }^{(6)}$.

Embora a grávida seropositiva corra sempre o risco de transmitir o vírus ao feto, verifica-se Que, apesar de muitas mulheres optarem pelo aborto, o número daquelas que decidem continuar com a gravidez é cada vez maior. Estas crianças nascidas sob a ameaça da vida constituem um desafio às mães contra a doença, constituindo uma outra razão à vida das mesma ${ }^{(25)}$.

\section{Efeitos da Infecção pelo VIH na Gravidez}

É relevante salientar Que não existem estudos conclusivos no Que respeita a uma correlação directa entre a gravidez e a evolução da infecção pelo VIH, no entanto, apesar do conhecimento dos efeitos da infecção pelo VIH na gravidez ainda ser reduzido, alguns autores fazem referência a possibilidade de complicações como, aborto espontâneo, morte in útero, parto prematuro, hipotrofia do feto ${ }^{(27)}$.

Esta autora acrescenta ainda Que estas complicações estão normalmente associadas a outros factores como más condições socio-económicas ou toxicodependência, e não necessariamente à seropositividade. De QualQuer forma, estas gestações devem ser consideradas de risco, devendo existir uma vigilância clínica constante.

Pensa-se Que a transmissão do VIH da mulher infectada para o feto e recém-nascido se processa de três formas: para o feto via circulação materna logo no primeiro trimestre; para o neonato durante o trabalho de parto e nascimento por inoculação ou ingestão de sangue materno e outros fluidos infectados; para o lactente através do leite materno ${ }^{(28)}$.

No caso de mulheres infectadas, levanta-se a Questão da mãe transmitir ou não a doença ao filho, sendo Que muitas das mulheres (entre 20\% a 40\%) dos chamados países subdesenvolvidos Que não fazem QualQuer tipo de tratamento transmitem o vírus aos seus filhos, contudo, o risco de transmissão dos subtipos de VIH não é igual, sendo Que o risco de transmissão do VIH2 é menor comparativamente ao $\mathrm{VIH}^{(29)}$. A transmissão dá-se através da placenta, ou do contacto do bebé com os fluidos vaginais da mãe durante o trabalho de parto ${ }^{(30)}$. Estima-se Que cerca de uma em Quatro crianças de mulheres seropositivas são infectados deste modo e cerca de $10 \%$ são infectados através do aleitamento ${ }^{(8)}$.

Muitas das mulheres (40\%) Que se encontram grávidas só têm conhecimento Que são portadoras do VIH após o primeiro exame pré-natal ${ }^{(2)}$. Uma das formas de atenuar o risco de contágio à criança passa por administrar Zidovudina (AZT) à mãe.

Os resultados têm-se mostrado bastantes satisfatórios, dado Que a possibilidade de transmissão diminui de $25 \%$ para $8 \%^{(2,3,13,31)}$.

Outra preocupação Que se coloca, no caso de uma mulher grávida seropositiva é na altura do parto tentar diminuir ao máximo o risco de contágio ao bebé.

Esse risco pode ser diminuído se, durante o parto normal, as vias genitais forem devidamente limpas de 4 em 4 horas ou de 6 em 6 horas com substâncias como virucidas especiais, se controlarem cortes auxiliares durante o parto Que poderão provocar sangramento (episiotomias), se desinfectar o cordão umbilical antes de o retirar da criança, e por último, se limpar a criança logo após o nascimento ${ }^{(2,13)}$. Nestes casos em Que a mãe é seropositiva são necessários cuidados redobrados na altura de amamentação da criança, dado Que no leito materno existe uma grande concentração de células infectadas com VIH; deve ser evitado dar leite materno ao bebé, só se devendo recorrer a esta forma de alimentação numa situação de subnutrição ${ }^{(13,31)}$.

O prognóstico para a infecção perinatal por VIH depende dos tipos de doenças secundárias Que esta desenvolva, no entanto verifica-se na sua maioria de um retardo no crescimento, hepatoesplenomegália, infecções recorrentes do trato respiratório, encefalopatia, entre outras ${ }^{(32)}$.

\section{Vivência Psicológica com a Grávida VIH}

Schaffer ${ }^{(20)}$ considera Que a infecção pelo VIH tem um efeito profundo nas mulheres como doença e como desafio social e económico. O VIH afecta o papel de cuidar dos outros da mulher na família, e as mulheres tem de lidar com uma doença Que ameaça as suas vidas eneuanto também lidam com o impacto da doença na sua família.

Jakobs citado por Pinto ${ }^{(27)}$, sublinha as dificuldades e conflitos interpessoais Que as mulheres têm de enfrentar ao tomarem conhecimento de uma gravidez e de uma infecção provocada pelo HIV na mesma altura. O autor constata o aumento dos níveis de stress induzido pela falta de informação, pela decisão a tomar acerca do futuro da gravidez e o stress resultante das hospitalizações a Que estariam sujeitas as mulheres, Quer optassem pela gravidez Quer pela sua interrupção.

A grávida seropositiva vê-se muitas vezes confrontada com a dor trazida pela perspectiva de ser a mãe Que dá vida e se transforma 
numa mãe "perigosa", portadora de morte, exigindo-lhe um esforço suplementar para tentar integrar esse facto.

Esses acontecimentos podem desencadear um conjunto de vivências negativas em Que podem aparecer: sentimentos de culpa, negação, angustias e uma auto-imagem de mãe e de mulher desvalorizada ${ }^{(25)}$. O medo da morte vai servir de pano de fundo para todos os seus actos pensamentos e sentimentos. As mães seropositivas não só se afligem com a perda antecipada de suas próprias vidas, mas também com a perda concomitante de suas crianças, família e amigo ${ }^{(7)}$.

Em contraposição, alguns autores referem Que o nascimento de um filho faz a doença praticamente desaparecer, pois a criança torna-se o centro das atenções e preocupações, conferindo um forte motivo para as mães lutarem contra a doença. Mas subjacente a esta força para enfrentar a vida existe a preocupação materna face ao receio de não poder criar os filhos, visto a SIDA ser uma doença fatal, ainda sem cura conhecida. Tendo consciência Que poderão adoecer rapidamente e não poderem acompanhar o desenvolvimento das suas crianças, estas mães antecipam-se na escolha de uma "segunda mãe" para os filhos, de maneira Que as crianças sejam capazes de investir noutras figuras maternas Que as poderão ajudar a elaborar o luto de suas mães ${ }^{(25)}$.

Os autores supracitados referem ainda Que o nascimento de uma criança em risco tem conseQuências sobre as vivências maternas e de organização da conduta do próprio bebé, o Que vai originar dificuldades de interacção entre a mãe e a criança. Assim, o nascimento de um bebé Que tem probabilidade de ser seropositivo, mas Que só é possível ter um diagnóstico definitivo alguns meses depois do parto, provoca nas mães, uma grande ansiedade, angústia e incerteza.

Ao concretizar-se o prognóstico da infecção pelo vírus VIH na criança, estas mães vão assistir à degradação progressiva das suas capacidades, o Que contribui para Que existam alterações na relação mãe-bebé.

As mulheres Que ficam grávidas durante a infecção por VIH ou Que contemplam a gravidez nessa circunstância precisam de informação sobre o risco para o feto, tal como informação em como cuidar da sua saúde. O estigma ligado ao VIH/SIDA pode sujeitar as mulheres a discriminação, perda de emprego, rejeição social, e outras violações dos seus direitos. Embora seja uma doença transmitida principalmente por via sexual, a SIDA e abordada singularmente devido ao efeito devastador Que tem tido nas mulheres infectadas e nas suas famílias, tal como devido a complexa gestão psicossocial e medica Que e necessária para retardar os efeitos e promover uma melhor Qualidade de vida nas mulheres infectadas $^{(20)}$.

\section{CONSIDERAÇÕES FINAIS}

A SIDA, enquanto fenómeno Que abrange toda a dimensão biopsicossocial do indivíduo, tem-se tornado, ao longo das últimas décadas, num campo privilegiado pela investigação científica em diferentes ramos do saber. Fruto desta constante investigação e evolução médica e medicamentosa, surge no panorama actual, em Que a seropositividade para o VIH assume cada vez mais os contornos de uma doença crónica, Que mistura problemas de ordem sanitária, exigências e reacções psicológicas, e necessidades ou preocupações de ordem social, Que implicam o repensar de todo um projecto de vida, e exige a aprendizagem e desenvolvimento de capacidades (comportamentais, cognitivas e emocionais) para gerir o dia a dia ${ }^{(6)}$.

As consequências de um diagnóstico de seropositividade para o VIH na mulher em idade fértil, são particularmente pesadas, pois acresce-se a todas as dificuldades inerentes ao confronto com a sua própria mortalidade, a decisão de desistir ou não de um aspecto importante da sua vida Que é a maternidade.

É relevante ter presente Que a transmissão materno-fetal de um vírus Que pode ser fatal para a mãe e para o seu bebé produz modificações importantes nas vivências da grávida seropositiva, Quer posteriormente no relacionamento mãe-bebé. Surge um sentimento de impotência e culpabilidade face à situação, o Que contribui para uma desvalorização da imagem de mãe e mulher ${ }^{(6)}$.

Neste sentido, as mães com VIH que decidem prosseguir com a gravidez, assistem desde o nascimento da criança, a um combate entre as forças da vida, da esperança, do futuro e as forças da morbidez, da discriminação, do isolamento, do sofrimento, do medo da doença e da morte. É um combate Que vai acompanhar sempre tanto a mãe como a criança ${ }^{(25)}$.

\section{REFERÊNCIAS}

1. Kalichman SC. Understanding AIDS: Advances in research and treatment. Washington: American Psychological Association; 1998.

2. Montagnier L. - Vírus e Homens: o combate contra a SIDA. Lisboa: Instituto Piaget; 1994.

3. Kalichman SC. Preventing AIDS: A sourcebook for behavioural interventions. New Jersey: Lawrence Erlbaum Associates; 1998.

4. Matos M. SIDA: prevenção impossível. Análise Psicol 1994; 2-3(12): 201-9.

5. O'Leary A, Wingood G. Interventions for sexually active heterosexual: women. In: Peterson JL, DiClemente RJ, editors. Handbook of HIV Prevention. Philadelphia: Saunders; 2000. p.179-97.
6. Cabral IP, Leal I. Congresso Nacional de Psicologia da Saúde Um olhar sobre um paradoxo: o desejo de maternidade, a percepção da doença e o suporte social em mulheres grávidas e mães seropositivas para o VIH. In: Ribeiro J, Leal I, Dias M, editores. Lisboa: ISPA; 2000. p. 323-37.

7. Teixeira IAC. Psicologia da saúde e SIDA. Lisboa: ISPA; 1993.

8. Straub RO. HIV and AIDS. Health Psychol 2002; 11 : 460-99.

9. Bauman K. Sexually transmitted diseases. In: Rosenfeld A, editor. Handbook of Women's Health: an evidence based approach. Cambridge: Cambridge University Press; 2001. p. 254-80.

10. Harvard Medical School. HIV/AIDS. Boston: Harvard Medical School; 2007 [citado em 02 Set 2007]. Disponível em: http:/ /www.intelihealth.com/IH/ihtlH/WSIHW000/408/408.html 
11. Ogden J. A Psicologia na evolução da doença: VIH, cancro e doença coronária. Psicologia da Saúde. Manuais universitários. Lisboa: Climepsi Editores; 1999.

12. Alvarez MI. Representações cognitivas e comportamentos sexuais de risco: o guião e as teorias implícitas da personalidade nos comportamentos de protecção sexual. Lisboa: Fundação Calouste Gulbenkian; 2005.

13. Cardoso AAFP. Prevenção primária da SIDA em jovens: avaliação de um projecto de prevenção: conhecimentos, comportamentos e atitudes [dissertação]. Porto: Universidade do Porto; 1999.

14. UNAIDS/UNICEF/World Health Organization. Epidemiological fact sheets on HIV/AIDS and sexualitity transmited infections. Genebra: UNAIDS/WHO; 2006.

15. European Centre for the Epidemiological Monitoring of HIV/ AIDS, WHO and UNAIDS Collaborating Centre on HIV/AIDS. Mid-year report: HIV/AIDS - surveillance in Europe. SaintMaurice: Euro HIV - HIV/AIDS Surveillance in Europe; 2007.

16. Comissão Nacional de Luta contra a SIDA. A situação em Portugal a 31 Dezembro de 1994. Lisboa: CNLCS; 1994.

17. Instituto Nacional de Saúde Dr. Ricardo Jorge \& Ministério da Saúde (PT). Centro de Vigilância Epidemiológica das Doenças Transmissíveis. Lisboa: Centro de Vigilância Epidemiológica das Doenças Transmissíveis; 2007.

18. Wijgert JV, Padian NS. Heterossexual transmission of HIV. In: Lorraine S, editor. AIDS and heterosexual population. Switzerland: Harwood Academic Publishers; 1993. p. 1-19.

19. Logan TK, Cole I, Leukefeld C. Women, Sex, and HIV: social and contextual factors, meta-analysis of published interventions, and implications for practice and research. Psychol Bull (APA) 2002; 6: 85 I-85.

20. Schaffer SD. Women and HIV. In: Quinn EY, Davis MS, editors. Women's health. A primary care clinical guide. $2^{\text {nd }}$ ed. East Norwalk: Appleton \& Lange; 1998. p. 301-12.
21. Ickovics I, Rodin J. Women in AIDS in the United States: epidemiology, natural history and mediating mechanisms. Health Psychol 1992; II(1): 1-16.

22. Carvalho IAT. A SIDA no feminino do plural: as mulheres e a infecção pelo VIH. Análise Psicol 1996; 14(2/3): 7-37.

23. Richardson D. La mujer y el SIDA. Cuidad del Mexico: Editorial el Manual Moderno; 1990.

24. Canavarro MC. Gravidez e maternidade - representações e tarefas de desenvolvimento. In: Canavarro MC, organizador. Psicologia da gravidez e da maternidade. $2^{\text {a }}$ ed. Coimbra: Quarteto; 2006. p. 17-49.

25. Nascimento SV, Pires A, Sota RMC. Mães com VIH. In: Pires A, editor. Crianças (e pais) em risco. Lisboa: ISPA; 2001 . p. 323-45.

26. Carvalho IAT. Psicologia da saúde e SIDA. Lisboa: ISPA; 1993.

27. Pinto ACM. SIDA, gravidez e maternidade. Análise Psicol 1995; 13(1/2): 73-7.

28. Poole J. Hipertensão, hemorragia e infecções maternas. In: Bobak I, Lowerdermilk D, Jensen M, editores. Enfermagem na maternidade. Loures: Lusociência; 1999. p. 579-643.

29. Adjorolo-Johnson G, De Cock KM, Ekpini E, Vetter KM, Sibailly T, Brattegaard K, et al . Prospective comparison of mother-tochild transmission of HIV-1 and HIV-2. IAMA 1994; 272: 462-6.

30. Rosenberg ZF, Fauci AS. Immunopathology and pathogenesis of human immunodeficiency virus infection. Pediatric Infect Dis I 1991; 10: 230-8.

31. Hankins C. Women and HIV infection. In: Lorraine S, editor. AIDS and heterosexual population. Switzerland: Harwood Academic Publishers; 1993. p. 2 I-39.

32. Whaley L, Wong F. Enfermagem pediátrica: a criança com disfunção hematológica ou imunológica. Rio de Janeiro: Guanabara Koogan; 2001 . 